\title{
LUT
}

University

\section{Fatigue strength assessment of ultra-high-strength steel fillet weld joints using $4 R$ method}

Ahola Antti, Skriko Tuomas, Björk Timo

This is a Post-print

version of a publication

published by Elsevier

in Journal of Constructional Steel Research

DOI: $\quad 10.1016 / j . j c s r .2019 .105861$

Copyright of the original publication: () 2019 Elsevier Ltd.

Please cite the publication as follows:

A. Ahola, T. Skriko, T. Björk (2020). Fatigue strength assessment of ultra-high-strength steel fillet weld joints using 4R method, Journal of Constructional Steel Research, article number 105861 (in press). The article has been published in its final form at https://doi.org/10.1016/j. jcsr.2019.105861

This is a parallel published version of an original publication.

This version can differ from the original published article. 
This is the accepted manuscript (post-print version) of the following article:

A. Ahola, T. Skriko, T. Björk (2020). Fatigue strength assessment of ultra-high-strength steel fillet weld joints using 4R method, Journal of Constructional Steel Research, article number 105861

(in press). The article has been published in its final form at https://doi.org/10.1016/j.jcsr.2019.105861

(C) 2019. This manuscript version is made available under the CC-BY-NC-ND 4.0 license http://creativecommons.org/licenses/by-nc-nd/4.0/ 


\title{
Fatigue strength assessment of ultra-high-strength steel fillet weld joints using $4 \mathrm{R}$ method
}

\author{
A. Ahola, T. Skriko, T. Björk \\ Laboratory of Steel Structures, Lappeenranta-Lahti University of Technology LUT, P.O. Box 20, FI- \\ 53851 Lappeenranta, Finland
}

\begin{abstract}
A fatigue analysis on experimentally tested transverse fillet-welded non-load-carrying T-and X-joints made of S960 and S1100 ultra-high-strength steel was carried out in the present study. The test data consisted of welded joints in the as-welded, high frequency mechanical impact-treated, and tungsten inert gas-dressed conditions, that were fatigue tested using uniaxial constant amplitude loading with an applied stress ratio of $R=0.1-0.5$. The weld geometry and residual stress measurements were carried out, and for each joint, the fatigue strength was assessed using a multiparametric notch stress approach, entitled the 4R method, which incorporates the consideration of four parameters, i.e. notch stress range $\Delta \sigma_{k}(r)$, applied stress ratio $R$, material ultimate strength $R_{m}$, and residual stress $\sigma_{r e s}$ in the fatigue assessment. In the $4 \mathrm{R}$ method, the local cyclic elastic-plastic behavior at the notch root is obtained, and the SmithWatson-Topper parameter is applied to conduct a mean stress correction to commeasure all results into a single $S$ - $N$ curve. The results showed that the applied stress ratio had a distinct influence on the fatigue strength capacity for both joints in the as-welded and post-weld treated conditions when using the conventional stress-based approaches, i.e. nominal stress, structural hot-spot stress and effective notch stress concepts. Nevertheless, the 4R method resulted in a good agreement between the experimental test results and the fatigue strength assessments, regardless of the load and joint conditions.
\end{abstract}

Keywords: Fatigue; welded joint; ultra-high-strength steel; post-weld treatment; 4R method 


\section{INTRODUCTION}

The use of ultra-high-strength steels (UHSSs) has gained increasing interest for many applications, such as in cranes, aerial work vehicles and transport equipment since UHSSs enable weight reduction with improved structural performance in comparison to conventional mild steels. However, to exploit the full potential of cyclically loaded structures made of welded UHSS components, the implementation of postweld treatments (PWTs) is essential, together with a convenient structural design and high fabrication quality. Numerous studies have been conducted in the field of high frequency mechanical impact (HFMI) treatment [1-5] and tungsten inert gas (TIG) dressing [6-8] on welded joints made of UHSS showing a significant improvement in fatigue strength capacity with respect to the $S-N$ curves for the corresponding joints in as-welded (AW) condition [9-12].

Conventionally, in the fatigue strength assessment of a welded joint in the AW condition, the presence of high tensile residual stresses is assumed. As a consequence, the increasing mean stress level of externally applied loading does not significantly decrease the fatigue strength capacity [13]. However, it is well-known that the applied stress ratio has a significant effect on the improvement level of the PWT methods if the fatigue strength improvement is based on the modified residual stress state at the notch root, such as in the HFMI treatment. The improvement level, obtained by the HFMI treatment, is also associated with the material strength [14]. Consequently, according to the IIW Recommendations [15], a higher improvement level can be claimed for a welded detail made of higher material strength, although a reduction in the improvement level depending on the $R$ ratio is proposed.

TIG dressing, by means of re-melting the transition region from the base material to the weld reinforcement, lowers the stress concentration at the weld toe, contributing to the achievement of high fatigue strength. The residual stress after the TIG dressing seems to be related to the microstructure 
properties of the base metal. Hensel et al. [16] reported near zero residual stresses for S355 steel and tensile residual stresses for S960QL steel, similar to Ahola et al. [17] for S1100QT steel. In contrast, Skriko et al. [6] reported compressive residual stresses for TIG-dressed S960QC weldments. In general, the potential existence of tensile residual stresses posits that the improvement due to the TIG dressing is less sensitive to the increase in the mean stress level.

The prevailing concept in engineering is that the different PWTs and load conditions $(R)$ are considered in the fatigue strength assessment by either introducing material strength-, PWT- and $R$ specific reduction or improvement factors, or using PWT-specific $S-N$ curves that are based on experimental verifications. Such factors can be applicable in many cases but might also result in redundant conservatism and, in particular, offer no physical explanation for the increase or reduction in the fatigue strength capacity. Hensel et al. [18,19] introduced a fatigue bonus factor related to the effective stress ratio that can be used to evaluate the effect of stabilized residual stress, in association with material strength and the external stress ratio, on fatigue strength capacity, but the factor lacks the consideration of notch stress concentrations potentially influenced by the welding technique or PWT.

Recently, various local approaches [20-22] have been introduced to evaluate fatigue strength of weld toe and weld root failures. However, high quality UHSS weldments without initial flaws, either in the AW or post-weld treated condition, require advanced methods to consider parameters affecting the fatigue performance. To overcome the issues related to the combined effect of the different load and residual stress conditions, in conjunction with material strength and notch stress concentration, on the fatigue strength capacity, Nykänen et al. [23-25] introduced a notch stress-based fatigue strength assessment approach, entitled the 4R method after the four parameters included in the analysis, i.e. notch stress range $\Delta \sigma_{k}(\boldsymbol{r})$, applied stress ratio $\boldsymbol{R}$, residual stress $\sigma_{\text {res }}$ and material ultimate strength $\boldsymbol{R}_{m}$, see bolded $R$ and $r$ letters as an introduction to the name. In the 4R method, the local stress ratio $R_{\text {local }}$ acting at the 
notch root is determined considering the aforementioned parameters. Material ultimate strength $R_{m}$ and residual stress state $\sigma_{\text {res }}$ determine the material behavior at the notch root under external cyclic load configuration, i.e. the applied notch stress range $\Delta \sigma_{k}$ based on the weld toe radius $r$ and applied stress ratio $R$. The well-known Smith Watson and Topper (SWT) equation [26], i.e. $\sigma_{\max } \varepsilon_{\mathrm{a}}=$ constant, is adopted in the fatigue strength assessment to consider the mean stress effect on the fatigue strength capacity. The applicability of the SWT parameter to the mean stress correction in welded joints has also been corroborated in $[27,28]$.

The applicability of the 4R method for various steel materials and grades, and applied stress ratios has been shown in the previous studies [24,29], while less has been paid attention to the UHSS joints in the post-weld treated condition. This study aims to verify the applicability of the 4R method for UHSS fillet weld joints in the AW and post-weld treated condition, including HFMI treatment and TIG dressing as PWT methods. Although UHSS fillet weld joints have been widely studied experimentally in recent years, geometry (weld profiles and weld toe radii) or residual stress measurements have not been conducted or reported precisely enough to apply the fatigue test data in the fatigue analyses using the $4 \mathrm{R}$ method. Consequently, experimental fatigue test data of UHSS fillet weld joints, reported in [17,30], are used as a basis of the fatigue analysis and in addition, fatigue tests in the AW and HFMI-treated condition are carried out for non-load-carrying X-joints (NLCX) made of S1100 UHSS grade to supplement the fatigue test data. The NLCX-joints in the AW condition are fatigue tested using $R=0.1$ and $R=0.5$ applied stress ratios of external loading. Based on the findings in a previous study [17], the HFMI-treated joints were tested with various $R$ values in the $R=0.1-0.4$ regime to investigate the effect of increased mean stress on the improvement level of the HFMI treatment. Comprehensive geometry and residual stress measurements are carried out for the test data, and the collected data are analyzed using the $4 \mathrm{R}$ method. 


\section{EXPERIMENTAL DATA}

\subsection{Applied fatigue test data}

In this study, the recently published fatigue test results were applied for the notch stress analysis. The fatigue test results with the relevant information related to the test specimens, such as the weld toe radius, residual stress condition and secondary bending stress, were collected from recent studies. Numerous experimental studies have been conducted on welded UHSS joints in the AW and PWT conditions, but either the secondary bending stress, residual stress or weld geometry (including weld toe radius, throat thickness and weld flank angle) measurements were not conducted precisely enough in terms of the $4 \mathrm{R}$ method or the results were not available. Consequently, fatigue test data of such studies were not included in this study. The applied data consisted of fillet-welded NLCT- and NLCX-joints. Table 1 summarizes the key information regarding the experimental test data. Further details regarding the preparation of the test specimens and measurements can be found in the original references [17,30].

Table 1. Fatigue test data of axially loaded transverse T- and X-joints included in this study.

\begin{tabular}{llllll}
\hline Ref. & Base material & Joint type & Joint condition & $R$ of external loading & No. of tests \\
\hline Ahola et al. $[17]$ & S1100 & T-joint & AW & 0.1 and 0.5 & 6 \\
& S1100 & T-joint & HFMI & 0.1 and 0.5 & 4 \\
& S1100 & T-joint & TIG & 0.1 and 0.5 & 4 \\
Ahola et al. $[$ [30] & S960 & T-joint & AW & 0.1 & 2 \\
& S960 & X-joint & AW & 0.1 & 2 \\
\hline
\end{tabular}

\subsection{Additional fatigue tests}

The fatigue tests were carried out for NLCX-joints made of S1100MC UHSS. Fig. 1 shows the shape and dimensions, and welding preparation of the test specimens, and Tables 2 and 3 present the nominal mechanical properties and chemical compositions of the base material and filler metal, respectively. All 
specimens were prepared using a robotic gas metal arc welding (GMAW) with a $\varnothing 1.0 \mathrm{~mm}$ Union X96 solid wire targeting a nominal throat thickness of $a=5 \mathrm{~mm}$. Total number of 12 specimens were prepared and fatigue tested, of which eight specimens were tested in the AW condition, and four specimens were tested in the HFMI-treated condition. Residual stress and geometry measurements (weld profiles and toe radii) were measured before fatigue testing, and the further details and results of those measurements can be found in Table 7 in Section 3.2.

The fatigue tests were carried out using uniaxial constant amplitude cyclic loading with applied stress ratios of $R=0.1-0.5$. The specimen-specific test condition (applies stress range and ratio) can be found in Appendix A. Each specimen was equipped with a strain gage installed at the $0.4 t$ distance from the weld toe, see Fig. 1d, to obtain macrogeometric bending stress induced by the angular misalignment of specimen. A servo-hydraulic testing machine, see Fig. 2a, was used in the fatigue tests and the applied failure criterion was the total rupture of the specimen. Fig. $2 \mathrm{~b}$ presents a rupture and polished crosssection of a failed specimen

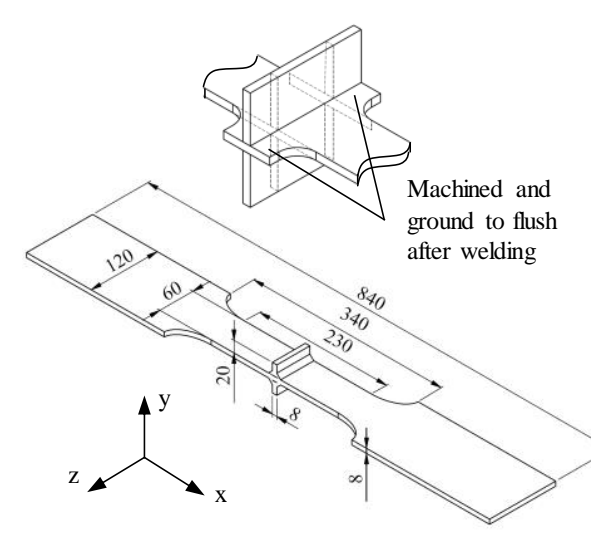

(a)
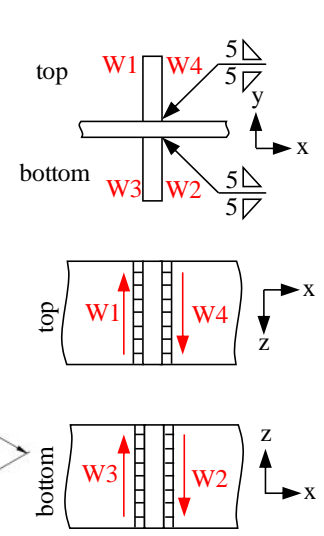

(b)
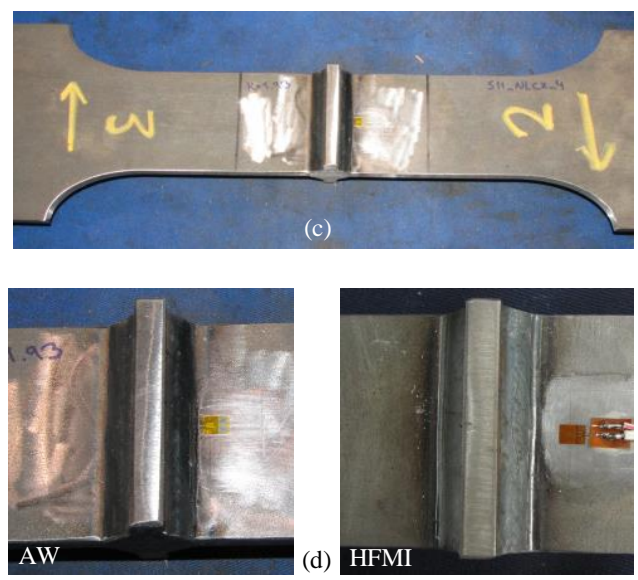

Fig. 1. NLCX fatigue test specimens tested within this study: (a) shape and dimensions of the test specimens (all dimensions in $\mathrm{mm}$ ), (b) sequence and direction of weld passes (W1-W4), (c) example of welded specimen, and (d) detailed views on joint areas and strain gages in specimens in the AW and HFMI-treated condition. 
Table 2. Nominal mechanical properties of the studied materials.

\begin{tabular}{lcccc}
\hline Material & Proof strength & Ultimate strength & Elongation & Impact Energy \\
& $R_{p 0.2, \min [\mathrm{MPa}]}$ & $R_{m}[\mathrm{MPa}]$ & $A_{5, \min }[\%]$ & $K V[\mathrm{~J}]($ at temp.) \\
\hline S1100 & 1100 & $1130-1350$ & 10 & $27\left(-40^{\circ} \mathrm{C}\right)$ \\
Union $\mathrm{X} 96^{1}$ & 930 & $\geq 980$ & 14 & $47\left(-50^{\circ} \mathrm{C}\right)$ \\
\hline
\end{tabular}

${ }^{1}$ Mechanical properties of undiluted weld metal

Table 3. Nominal chemical composition [weight-\%] of the studied materials (the most important alloying components).

\begin{tabular}{lllllll}
\hline Material & $\mathrm{C}_{\max }$ & $\mathrm{Si}_{\max }$ & $\mathrm{Mn}_{\max }$ & $\mathrm{P}_{\max }$ & $\mathrm{S}_{\max }$ & $\mathrm{Al}_{\min }$ \\
\hline $\mathrm{S} 1100$ & 0.20 & 0.50 & 1.80 & 0.02 & 0.005 & 0.015 \\
& $\mathrm{C}_{\max }$ & $\mathrm{Si}_{\max }$ & $\mathrm{Mn}_{\max }$ & $\mathrm{Cr}_{\max }$ & $\mathrm{Ni}_{\max }$ & $\mathrm{Mo}_{\max }$ \\
\cline { 2 - 7 } Union X96 & 0.12 & 0.8 & 1.9 & 0.45 & 2.35 & 0.55 \\
\hline
\end{tabular}

${ }^{1}$ Chemical composition of undiluted weld metal

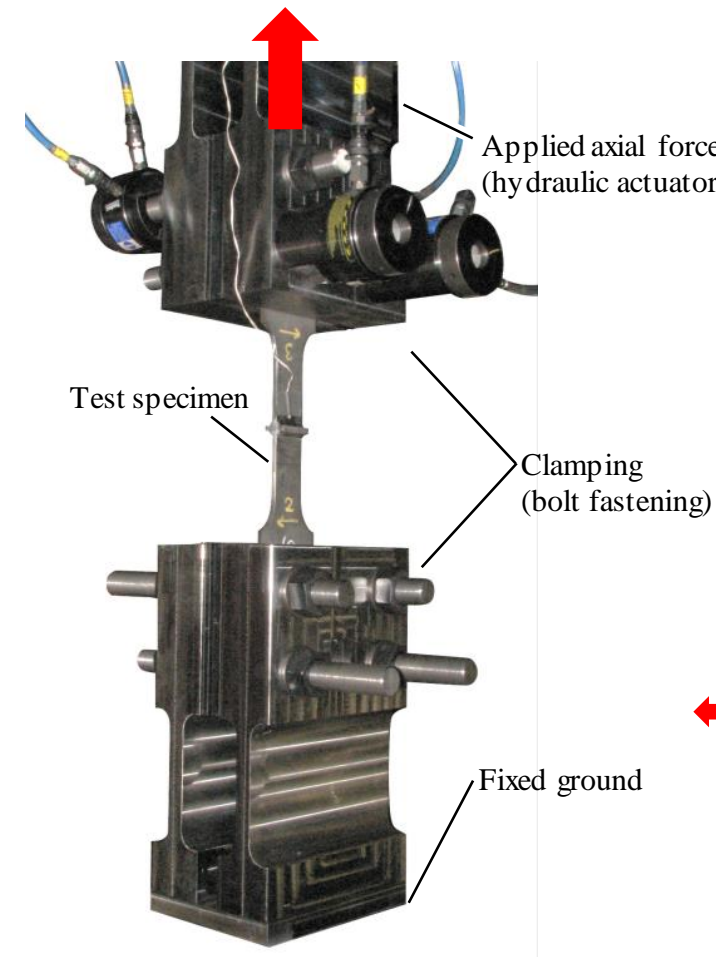

(a)

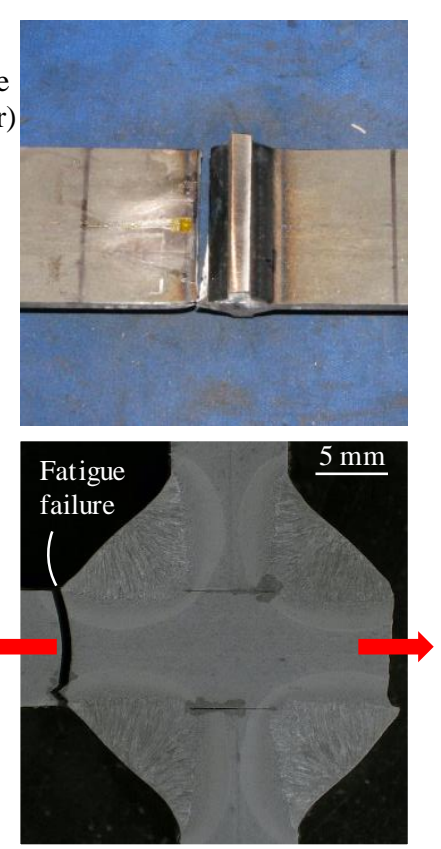

(b)

Fig. 2. (a) Fatigue test set-up, and (b) rupture and polished cross-section of a failed specimen. 


\subsection{Results}

The fatigue test data points are presented in Appendices A and B. The details regarding the geometry and residual stress measurements can be found in Section 3.2. A standard statistical analysis [9], with the free and fixed slopes of the $S$ - $N$ curve, was conducted on the test results. Due to the distinguishing notch stress factors and amount of the secondary bending stress induced by the angular distortion [30], the NLCT and NLCX joints showed different fatigue strength capacities in the nominal and structural stress systems. In the ENS system, all test results were embedded in the same statistical analysis. For the joints in the AW condition, a fixed $m=3$ slope was used while for the TIG-dressed and HFMI-treated joints, $m=4$ [31] and $m=5$ [15] were applied, respectively. Fig. 3 shows the data point plots with the corresponding standard or recommended curves, and Tables 4-6 present the results of the statistical analyses regarding the fatigue strengths. FE modeling and analysis were employed to obtain stress concentration factors (SCFs) for the ENS analysis. According to the ENS approach, fictitious weld toe radius of $r_{r e f}=1.0 \mathrm{~mm}$ has been suggested for AW and HFMI-treated specimens [15,32], and this approach was also used in this study. For the TIG-dressed joints, the $r_{\text {true }}+1 \mathrm{~mm}$ concept was used due to the large weld toe radius. A typical element mesh used in the analyses is presented in Fig. 8 (Section 3.2). The SCFs were obtained separately for membrane and bending stress (see Table 7), and the ENS was calculated as follows:

$$
\Delta \sigma_{e n s}=K_{t, m}(r=1 \mathrm{~mm}) \Delta \sigma_{m}+K_{t, b}(r=1 \mathrm{~mm}) \Delta \sigma_{b},
$$


where $\Delta \sigma_{e n s}$ is the ENS range, $K_{t, m}$ and $K_{t, b}$ are the SCFs for membrane and bending stress, respectively, $\Delta \sigma_{m}$ is the membrane stress due to the axial loading, and $\Delta \sigma_{b}$ is the bending stress induced by the macrogeometric angular distortion, and measured by a strain gage during the test.

(a)

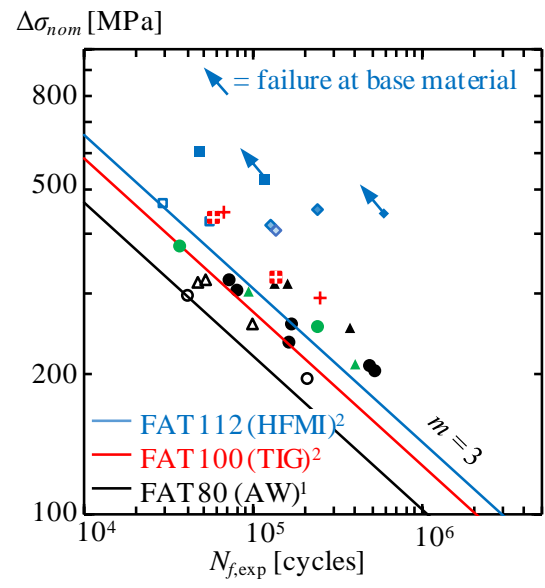

(b)

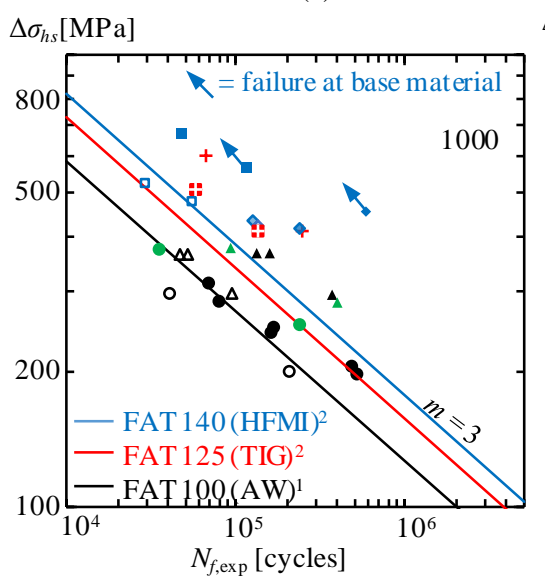

(c)

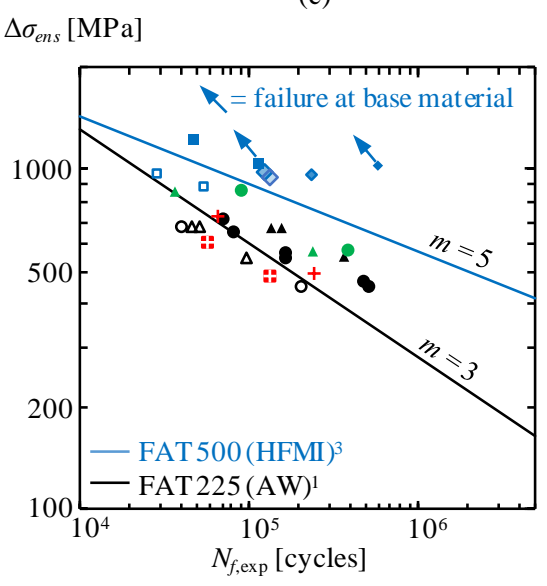

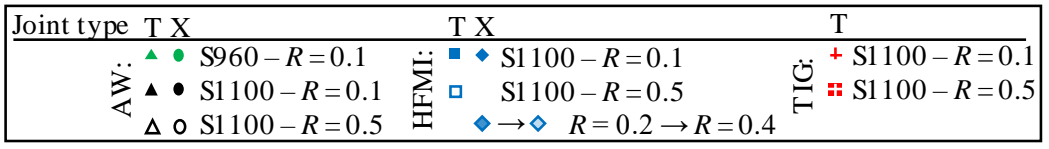

Fig. 3. Data points with the reference $S-N$ curves for the AW and PWT joints after ${ }^{1}$ Haagensen and Maddox [33], ${ }^{2}$ Hobbacher [9] and ${ }^{3}$ Marquis and Barsoum [15] in the (a) nominal stress $\Delta \sigma_{\text {nom }}$, (b) structural stress $\Delta \sigma_{h s}$, and (c) ENS system $\Delta \sigma_{e n s}\left(r_{r e f}=1.0 \mathrm{~mm}\right) . N_{f \text {,exp }}$ is the experimental fatigue life.

Table 4. Obtained mean fatigue strengths for the joints in the AW and PWT condition in the nominal stress system (survival probability of $P_{s}=50 \%$ ).

\begin{tabular}{|c|c|c|c|c|c|c|c|c|}
\hline \multirow{3}{*}{$\begin{array}{l}\text { Joint type } \\
\text { Stress ratio }\end{array}$} & \multicolumn{4}{|c|}{$m=$ fixed } & \multicolumn{4}{|c|}{$m=$ free } \\
\hline & \multicolumn{2}{|r|}{0.1} & \multicolumn{2}{|c|}{0.5} & \multicolumn{2}{|c|}{0.1} & \multicolumn{2}{|c|}{0.5} \\
\hline & $m$ & $\begin{array}{c}\text { FAT } \\
{[\mathrm{MPa}]}\end{array}$ & $m$ & $\begin{array}{c}\text { FAT } \\
{[\mathrm{MPa}]}\end{array}$ & $m$ & $\begin{array}{c}\text { FAT } \\
{[\mathrm{MPa}]}\end{array}$ & $m$ & $\begin{array}{c}\text { FAT } \\
{[\mathrm{MPa}]}\end{array}$ \\
\hline NLCT - AW & 3 & 126 & 3 & 92 & 3.26 & 134 & 3.11 & 96 \\
\hline NLCT - HFMI & 5 & 285 & 5 & 204 & $\mathrm{n} / \mathrm{a}$ & $\mathrm{n} / \mathrm{a}$ & 6.93 & 253 \\
\hline NLCT - TIG & 4 & 181 & 4 & 172 & 3.00 & 144 & 2.87 & 127 \\
\hline NLCX - AW & 3 & 111 & 3 & 86 & 4.29 & 144 & 3.98 & 110 \\
\hline
\end{tabular}


Table 5. Obtained mean fatigue strengths for the joints in the AW and PWT conditions in the HS stress $\operatorname{system}\left(P_{s}=50 \%\right)$.

\begin{tabular}{|c|c|c|c|c|c|c|c|c|}
\hline \multirow{3}{*}{$\begin{array}{l}\text { Joint type } \\
\text { Stress ratio }\end{array}$} & \multicolumn{4}{|c|}{$m=$ fixed } & \multicolumn{4}{|c|}{$m=$ free } \\
\hline & \multicolumn{2}{|r|}{0.1} & \multicolumn{2}{|c|}{0.5} & \multicolumn{2}{|c|}{0.1} & \multicolumn{2}{|c|}{0.5} \\
\hline & $m$ & $\begin{array}{c}\text { FAT } \\
{[\mathrm{MPa}]}\end{array}$ & $m$ & $\begin{array}{c}\text { FAT } \\
{[\mathrm{MPa}]}\end{array}$ & $m$ & $\begin{array}{c}\text { FAT } \\
{[\mathrm{MPa}]}\end{array}$ & $m$ & $\begin{array}{c}\text { FAT } \\
{[\mathrm{MPa}]}\end{array}$ \\
\hline NLCT - AW & 3 & 155 & 3 & 107 & 4.72 & 205 & 3.32 & 119 \\
\hline NLCT - HFMI & 5 & 315 & 5 & 228 & $\mathrm{n} / \mathrm{a}$ & $\mathrm{n} / \mathrm{a}$ & 7.57 & 297 \\
\hline NLCT - TIG & 4 & 250 & 4 & 209 & 3.45 & 219 & 3.90 & 205 \\
\hline NLCX - AW & 3 & 111 & 3 & 87 & 4.33 & 144 & 4.09 & 114 \\
\hline
\end{tabular}

Table 6. Obtained mean fatigue strengths for the joints in the AW and PWT conditions in the ENS system using the reference radius of $r_{r e f}=1.0 \mathrm{~mm}\left(P_{s}=50 \%\right)$.

\begin{tabular}{|c|c|c|c|c|c|c|c|c|}
\hline \multirow{3}{*}{$\begin{array}{l}\text { Joint type } \\
\text { Stress ratio }\end{array}$} & \multicolumn{4}{|c|}{$m=$ fixed } & \multicolumn{4}{|c|}{$m=$ free } \\
\hline & \multicolumn{2}{|r|}{0.1} & \multicolumn{2}{|c|}{0.5} & \multicolumn{2}{|r|}{0.1} & \multicolumn{2}{|c|}{0.5} \\
\hline & $m$ & $\begin{array}{c}\text { FAT } \\
{[\mathrm{MPa}]}\end{array}$ & $m$ & $\begin{array}{c}\text { FAT } \\
{[\mathrm{MPa}]}\end{array}$ & $m$ & $\begin{array}{c}\text { FAT } \\
{[\mathrm{MPa}]}\end{array}$ & $m$ & $\begin{array}{c}\text { FAT } \\
{[\mathrm{MPa}]}\end{array}$ \\
\hline All joints - AW & 3 & 269 & 3 & 200 & 4.15 & 338 & 3.71 & 246 \\
\hline All joints - HFMI & $5^{*}$ & $586^{*}$ & 5 & 425 & $4.97^{*}$ & $584^{*}$ & 7.89 & 564 \\
\hline All joints $-\mathrm{TIG}^{* *}$ & 4 & 303 & 4 & 252 & 3.33 & 264 & 3.92 & 248 \\
\hline
\end{tabular}

*All test results of $R=0.1-0.4$ but excluding base material failures (see Appendices $\mathrm{A}$ and $\mathrm{B}$ ). ${ }^{* *} r_{\text {ref }}=r_{\text {true }}+1 \mathrm{~mm}=7.4 \mathrm{~mm}($ see Table 7 , Section 3.2)

\section{4R FATIGUE ANALYSIS}

\subsection{Theoretical background}

The 4R method is a notch stress-based approach for the fatigue strength assessment of welded joints. In the $4 \mathrm{R}$ method, the material cyclic behavior is simulated considering the material strength, residual stress, weld toe quality, and thus the effective notch stress acting at the notch root, and the applied stress ratio of external loading. Effective notch stress with the stress averaging concept, i.e. $r=r_{\text {true }}+1 \mathrm{~mm}$, is used as a basis for the fatigue analysis. In a prior investigation [24], $r=1 \mathrm{~mm}$ was also used for the HFMItreated joints but within this study, the $r=r_{\text {true }}+1 \mathrm{~mm}$ concept is applied and proposed for these joints. 
The Ramberg-Osgood elastic-plastic material model with the kinematic hardening rule is applied to describe the material cyclic behavior at the notch root, which can be formulated as follows:

$$
\begin{aligned}
& \varepsilon=\varepsilon_{e}+\varepsilon_{p}=\frac{\sigma}{E}+\left(\frac{\sigma}{H}\right)^{\frac{1}{n}}, \\
& \Delta \varepsilon=\Delta \varepsilon_{e}+\Delta \varepsilon_{p}=\frac{\Delta \sigma}{E}+2\left(\frac{\Delta \sigma}{2 H}\right)^{\frac{1}{n}},
\end{aligned}
$$

where $\varepsilon, \varepsilon_{e}, \varepsilon_{p}$ are the total, elastic, and plastic strain, respectively, $\sigma$ is the stress, $E$ is the modulus of elasticity, $H$ is the strain hardening coefficient and $n$ is the strain hardening exponent. In Eq. (3), the symbols denoted with $\Delta$ represent the same variables but correspond to the range values. Neuber's rule with hyperbolae and counterhyperbolae are employed to obtain maximum and minimum stress, respectively, as follows:

$$
\begin{aligned}
& \varepsilon=\frac{\left(\frac{\Delta \sigma_{k}}{1-R}+\sigma_{k, r e s}\right)^{2}}{\sigma E}, \\
& \Delta \varepsilon=\frac{\Delta \sigma_{k}^{2}}{\Delta \sigma E},
\end{aligned}
$$

where $\Delta \sigma_{k}$ is the notch stress range obtained using the $r=r_{\text {true }}+1 \mathrm{~mm}$ concept, $R$ is the external stress ratio, and $\sigma_{k, \text { res }}$ is the local residual stress. Within the fatigue tests conducted in this and prior studies, relaxed and subsequently stabilized residual stresses were not measured during the fatigue test. For that reason, the initial residual stress state was assumed with conservative assumptions, see Section 3.2. Fig. 4 summarizes the key aspects related to the determination of local stress ratio $R_{\text {local }}$ at the notch root on the basis of the aforementioned concepts for the different residual stress states with and without residual stress relaxation, including the following steps: 
a. At the notch root, linear elastic effective notch stress $\left(\sigma_{k}\right)$ fluctuates cyclically under external constant amplitude loading and as a result, a time-stress history is received;

b. Local residual stress $\left(\sigma_{k, r e s}\right)$ can be tensile or compressive depending on the joint condition. Local residual stress posits the initial stress occurring at the notch root, i.e. the starting point at the R-O curve in Fig. 4c is derived. The relaxation of residual stresses can be taken into account by changing the starting point at the R-O curve;

c. The local cyclic behavior and, subsequently, the hysteresis loops are determined based on the effective notch stress range and the initial residual stress. As a result, the local minimum and maximum stress $\left(\sigma_{\min }\right.$ and $\left.\sigma_{\max }\right)$ acting at the notch are derived.

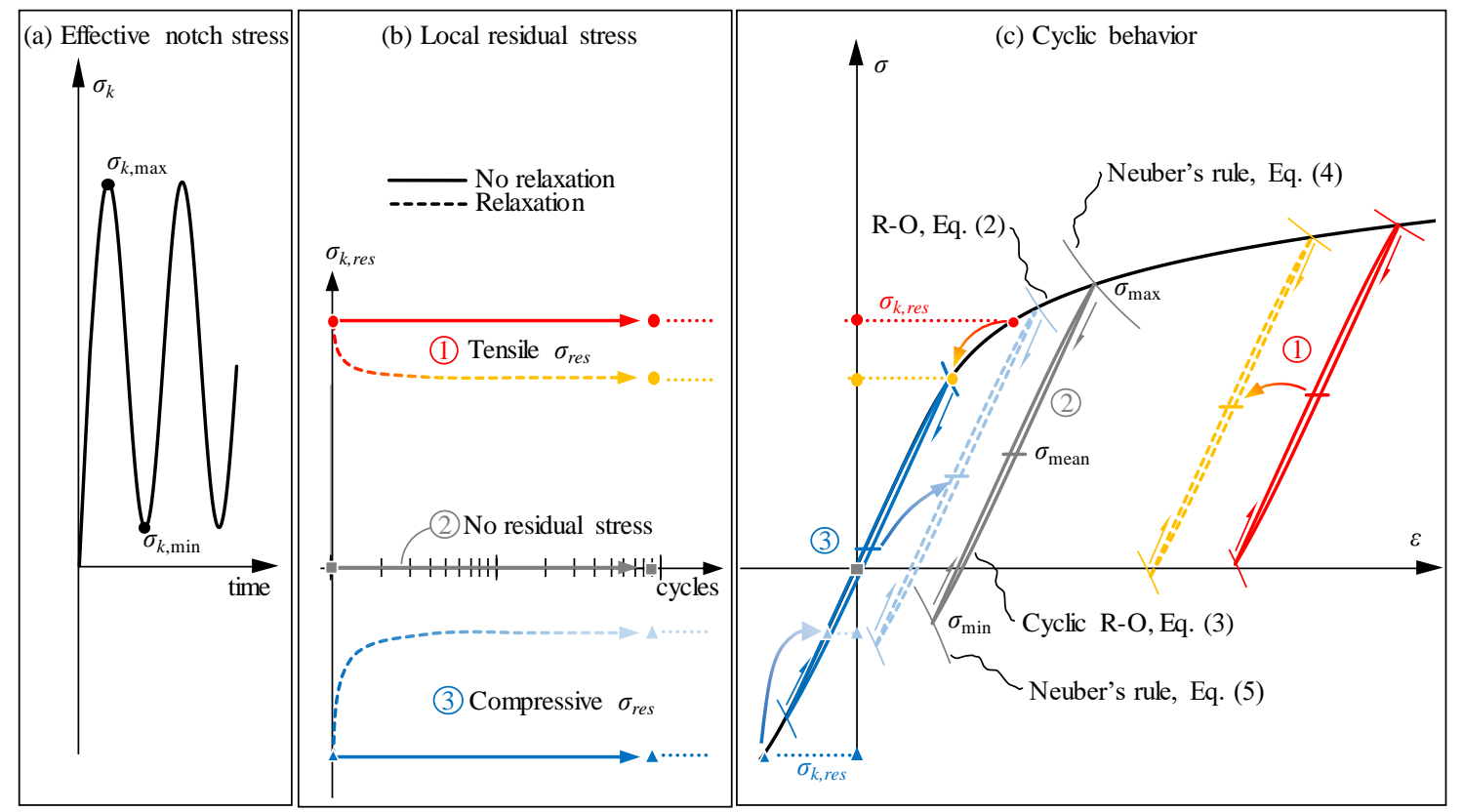

Fig. 4. Schematic representation of cyclic behavior following Eqs (2-5): (a) constant amplitude effective notch stress due to external loading, (b) local residual stresses at the notch root with and without the residual stress relaxation, and (c) cyclic behavior and hysteresis loops influenced by the effective notch stress range and residual stresses. 
Both tensile and compressive welding residual stresses can significantly relax under cyclic loading [34,35]. As shown in Fig. 4, the stabilization of residual stress in the case of compressive residual stresses, e.g. as a result of the HFMI treatment, increase distinctly mean stress level of local stress ratio. A decrease in the high residual stress, however, does not have a significant influence on the mean stress level, as local yielding occurs with the maximum loading even at the low level of loading. Nevertheless, is must be noted that the given example is presented for a cyclic loading at the low stress ratio, i.e. $R=0.1$, and at high stress ratios, the effect of residual stress state on the cyclic behavior and subsequently on the fatigue strength is lower. The ratio of the local minimum and maximum stresses $\left(\sigma_{\min }\right.$ and $\left.\sigma_{\max }\right)$ determine the local stress ratio $R_{\text {local }}$, whereby the reference notch stress range $\Delta \sigma_{k, r e f}$ can be defined by reformulating the SWT parameter [24] as follows:

$$
\begin{aligned}
& R_{\text {local }}=\frac{\sigma_{\min }}{\sigma_{\max }} \\
& \Delta \sigma_{k, \text { ref }}=\frac{\Delta \sigma_{k}\left(r_{\text {true }}+1 \mathrm{~mm}\right)}{\sqrt{1-R_{\text {local }}\left[\Delta \sigma_{k}\left(r_{\text {true }}+1 \mathrm{~mm}\right), n, H, \sigma_{\text {res }}, R_{\text {eff }}\right]}},
\end{aligned}
$$

where $R_{\text {eff }}$ is the effective stress ratio (see further details in Section 3.2). Further details concerning the theoretical background of the $4 \mathrm{R}$ method can be found in references [23,24,29].

\subsection{R parameters}

The tests were conducted mainly at the intermediate life, i.e. around 100000 cycles with a maximum ENS of $1000 \mathrm{MPa}$; no reversed plasticity was present in the tests with the studied high-strength materials, and fully elastic stress ranges can be assumed. If no cyclic softening or hardening is assumed, the monotonic stress-strain-behavior describes the material behavior in the tests. In a recent study, Amraei et al. [36] determined the material behavior of the studied S960 and S1100 grades in non-welded and butt-welded components. From these tests, the Ramberg-Osgood (R-O) material models for the base 
materials can be obtained. The engineering force-displacement behavior was converted to true stress-true strain curves and subsequently, the plastic strain characteristics were derived for the R-O material models by conducting a linear regression analysis on the plastic strain and true stress, as shown in [37]:

$$
\log \varepsilon_{p}=\frac{1}{n}(\log \sigma-\log H)
$$

Young's moduli for the S960 and S1100 materials were determined on the basis of the digital image correlation (DIC) system, and $E_{\mathrm{S} 960}=204 \mathrm{GPa}$ and $E_{\mathrm{S} 1100}=209 \mathrm{GPa}$ were derived [36]. Fig. 5 presents the obtained material models for the studied S960 and S1100 base materials.

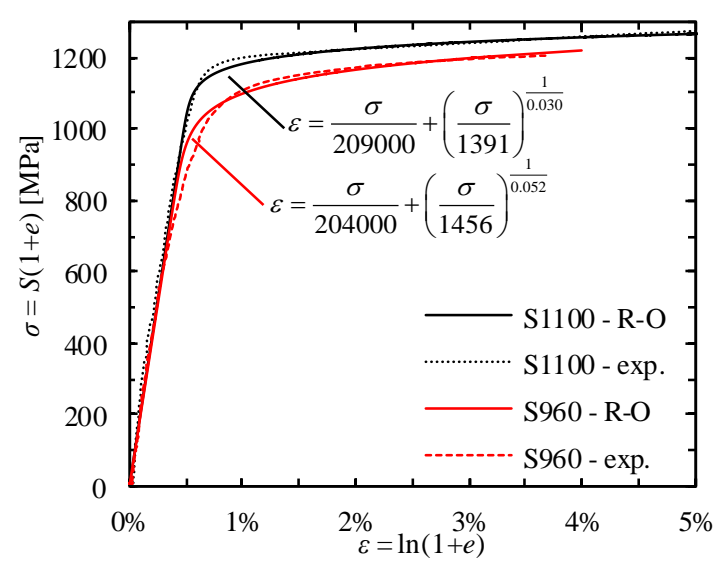

Fig. 5. Material models of the S960 and S1100 steels used in this study. $\varepsilon$ and $\sigma$ are the true strain and stress, respectively, obtained from the corresponding engineering values $(e, S)$ determined on the basis of the test force and displacement.

The fatigue tests were carried out using the applied stress ratios from $R=0.1$ to $R=0.5$. However, due to the angular distortion of the specimens, the clamping led to an additional increase in the mean stress level, as also shown by Leitner [38]. Thus, each specimen was equipped with a strain gage and the clamping-induced stress was recorded when the specimens were inserted into the test rig. Appendices A and B provide the effective stress ratio $\left(R_{e f f}\right)$ values, in which the clamping-induced bending stress, the 
straightening of the specimen due to axial loading, and the distinguishing notch factors [30] were considered as follows:

$$
R_{e f f}=\frac{K_{t, m} \sigma_{m, \min }+K_{t, b}\left(\sigma_{b, \text { clamping }}+\sigma_{b, \min }\right)}{K_{t, m} \sigma_{m, \max }+K_{t, b}\left(\sigma_{b, \text { clamping }}+\sigma_{b, \max }\right)}
$$

where $\sigma_{m, \min }$ and $\sigma_{m, \max }$, and $\sigma_{b, \min }$ and $\sigma_{b, \max }$ are the minimum and maximum of membrane and bending stresses, respectively, induced by the axial loading and the angular distortion in the test. In the NLCX joints, no significant clamping-induced bending stress was found, i.e. $\sigma_{b \text {,clamping }}<10 \mathrm{MPa}$, while the highest stresses due to the clamping were recorded in the TIG-dressed T-joints due to high angular distortion caused by the asymmetric joint geometry and thus, unequal welding and PWT heat inputs. In the TIG-dressed specimens, clamping stresses up to $\sigma_{b \text {,clamping }}=90 \mathrm{MPa}$ were found, see Fig. 6a. The surface residual stresses, parallel to the loading direction, were measured using an X-ray diffractometer (Stresstech X3000 G3 device) at the centerline of the specimens. In the 4R analysis, the characteristic maximum value of residual stress representative of joint type and condition was used since there was variation in the measurements, as shown in Fig. 6b, and the failure did not always occur at the center of the specimen where the measurements were conducted. For the HFMI-treated joints, relaxation of the residual stresses during the early stage of cyclic loading has been demonstrated by Leitner et al. [34]. Although the chosen maximum values for the HFMI-treated joints distinguish from the measured values up to $900 \mathrm{MPa}$ compressive residual stresses, see Fig. 6b, it can be noted that due to the relaxation, the stabilized residual stresses are lower in compression. However, in the studied joints, the stabilized residual stresses were not measured during the fatigue tests. 
(a)

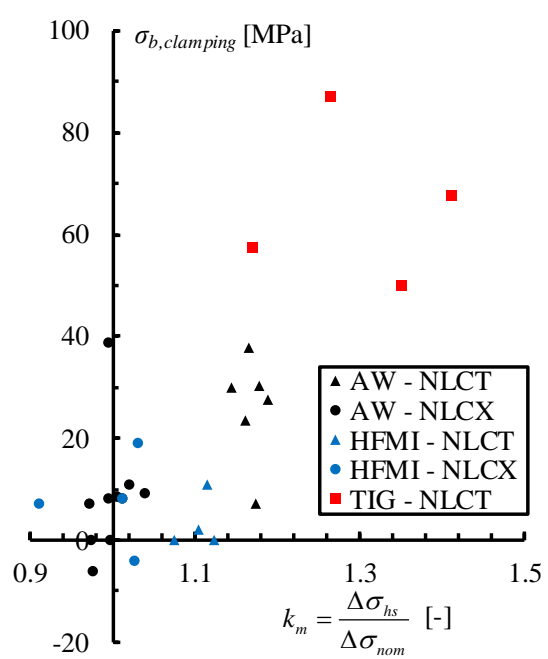

(b)

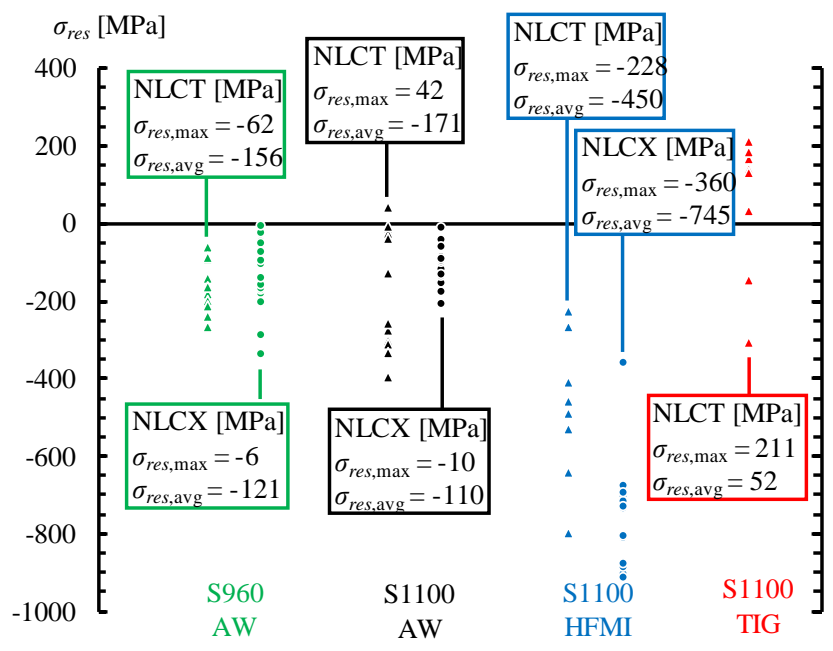

Fig. 6. (a) Clamping-induced stresses as a function of $k_{m}$ factor in the test, and (b) results of residual stress measurements for the NLCT and NLCX specimens in the AW and PWT condition.

Geometry measurements were conducted for all specimens and welds at the centerline of the specimens using a 2D coordinate measuring device with an inductive displacement transducer and a laser displacement sensor, see Fig. 7a. Based on the measurements, the weld toe radius $r_{\text {true }}$, flank angle $\theta$ and throat thickness $a$ were determined, see Fig. 7b. A summary of these analyses can be found in Table 7 . From the obtained geometry, a 2D quadratic 8-node plane strain element model with both $r=1 \mathrm{~mm}$ and $r=r_{\text {true }}+1 \mathrm{~mm}$ weld toe radius was modeled and analyzed to obtain SCFs for notch stress analyses (the ENS concept and 4R method). At the notch root, the element size of $r / 20$, e.g. element size of $0.05 \mathrm{~mm}$ $\times 0.05 \mathrm{~mm}$ for a weld toe radius of $1 \mathrm{~mm}$, was chosen based on the mesh convergence study on notch stresses undertaken by Baumgartner and Bruder [39]. All analyses were carried out using Femap (Siemens PLM Software) with Nx Nastran. Since all specimens were prepared using a robotic GMAW, almost constant weld profile was obtained, as indicated by the standard deviations (Stdv) of the measured values. As shown in Table 7, in the HFMI-treated and TIG-dressed specimens higher scatter was found 
regarding the weld toe radius as the treatments were conducted manually. Consequently, no specimenspecific finite element analysis (FEA) was carried out, instead the average (avg) values were used in each model representing the test series. Fig. 8a shows the load and boundary conditions applied in the models and Fig. $8 \mathrm{~b}$ presents FEA results. For the $4 \mathrm{R}$ method, the acting notch stresses $\Delta \sigma_{k}$ were obtained using Eq. (1) except now the SCFs based on $r=r_{\text {true }}+1 \mathrm{~mm}$ were used in the analysis.

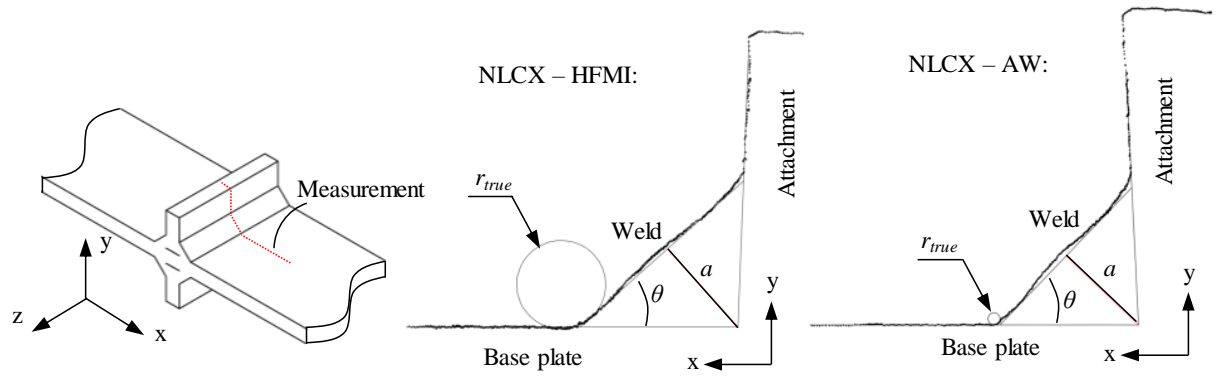

Fig. 7. (a) Measurement line of 2D geometry measurement and (b) results of the measurements of NLCX joints made of S1100 steel in the AW and HFMI-treated condition (see measured values in Table 7).

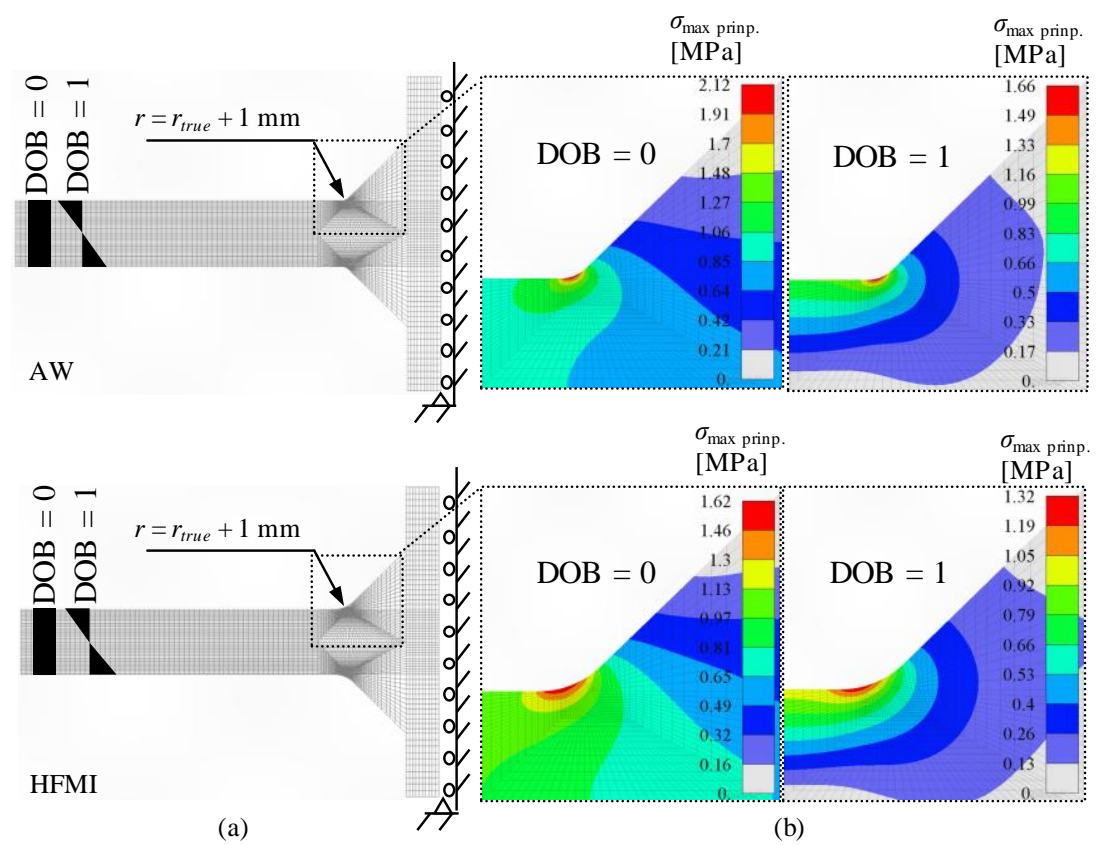

Fig. 8. (a) Half-symmetric FE models of the NLCX joints in the AW and HFMI-treated conditions with load and boundary conditions, and (b) the corresponding results of the SCFs for membrane and bending 
loading (a seed load of $1 \mathrm{MPa}$ was used in the analysis). DOB is the degree of bending (bending stress divided by the total stress).

Table 7. Average values and corresponding standard deviations for geometric variables derived from the 2D geometry measurements along with the corresponding SCFs. $n$ is the number of measurements conducted within each test group.

\begin{tabular}{|c|c|c|c|c|c|c|c|c|c|c|c|c|}
\hline \multirow[b]{2}{*}{ Group } & \multirow{2}{*}{$\begin{array}{l}\text { Joint } \\
\text { type }\end{array}$} & \multicolumn{7}{|c|}{ Weld geometry measurements } & \multicolumn{2}{|c|}{$\mathrm{SCF}(r=1 \mathrm{~mm})$} & \multicolumn{2}{|c|}{$\operatorname{SCF}\left(r=r_{\text {true }}+1 \mathrm{~mm}\right)$} \\
\hline & & $r_{\text {true }, \text { avg }}$ & $\operatorname{Stdv}_{r}$ & $\theta_{\text {avg }}$ & $\operatorname{Stdv}_{\theta}$ & $a_{\text {avg }}$ & $S t d v_{a}$ & $n$ & $K_{t, m}$ & $K_{t, b}$ & $K_{t, m}$ & $K_{t, b}$ \\
\hline S960 - AW [30] & NLCT & 0.30 & 0.07 & 43 & 1.1 & 5.1 & 0.12 & 24 & 1.85 & 2.06 & 1.73 & 1.90 \\
\hline S960 - AW [30] & NLCX & 0.29 & 0.07 & 43 & 1.5 & 5.2 & 0.17 & 12 & 2.32 & 1.79 & 2.14 & 1.66 \\
\hline S1100 - AW [17] & NLCT & 0.35 & 0.22 & 36 & 1.2 & 4.5 & 0.16 & 12 & 1.85 & 2.03 & 1.71 & 1.87 \\
\hline S1100 - HFMI [17] & NLCT & 2.3 & 0.49 & 37 & 1.7 & 4.5 & 0.09 & 8 & 1.85 & 2.03 & 1.38 & 1.48 \\
\hline S1100 - TIG [17] & NLCT & 6.4 & 1.8 & 37 & 1.5 & 4.5 & 0.11 & 8 & 1.85 & 2.03 & 1.20 & 1.24 \\
\hline S1100 - AW this study & NLCX & 0.3 & 0.11 & 44 & 1.9 & 5.2 & 0.18 & 32 & 2.30 & 1.78 & 2.12 & 1.66 \\
\hline S1100 - HFMI this study & NLCX & 2.3 & 0.21 & 43 & 2.3 & 5.2 & 0.23 & 16 & 2.30 & 1.78 & 1.62 & 1.32 \\
\hline
\end{tabular}

\subsection{Fatigue strength predictions}

Utilizing the concept introduced in Section 3.1 and the parameters presented in Section 3.2, the elastic plastic cyclic behavior was obtained for each test. For the test results $\left(\Delta \sigma_{k, r e f, i}, N_{f, i}\right)$, Deming's regression [40], i.e. minimization of the sum of the squared perpendicular distances (MSSPD), was conducted. Conventionally, in regression analysis, only the scatter in the fatigue life is determined and considered. However, since the $S-N$ curve is meant to describe the fatigue strength characteristics, and there is always uncertainty related to the stress acting at the local point causing the fatigue failure, the scatter should be regarded also in the stress value. Consequently, the stress range becomes partly unknown variable and the use of the MSSPD approach is justifiable. Fig. 9 shows all the fatigue test results presented in terms of the reference stress range $\Delta \sigma_{k, r e f}$ with the corresponding $S$ - $N$ curves. The $S-N$ curve of the $4 \mathrm{R}$ method can presented as follows: 


$$
N_{f, 4 \mathrm{R}}=\left(\frac{\sqrt{1-R_{\text {local }}}}{\Delta \sigma_{k}}\right)^{m_{4 \mathrm{R}}} C_{4 \mathrm{R}},
$$

where the $C_{4 \mathrm{R}}$ is the fatigue capacity and $m_{4 \mathrm{R}}$ is the slope of the $S-N$ curve according to the $4 \mathrm{R}$ method. Fig. 10 presents the fatigue test results corresponding to the notch stress range, and the $\mathrm{S}-\mathrm{N}$ curves are obtained from the reference curve, which is modified according to the $R_{\text {local }}$ values following Eq. (10).

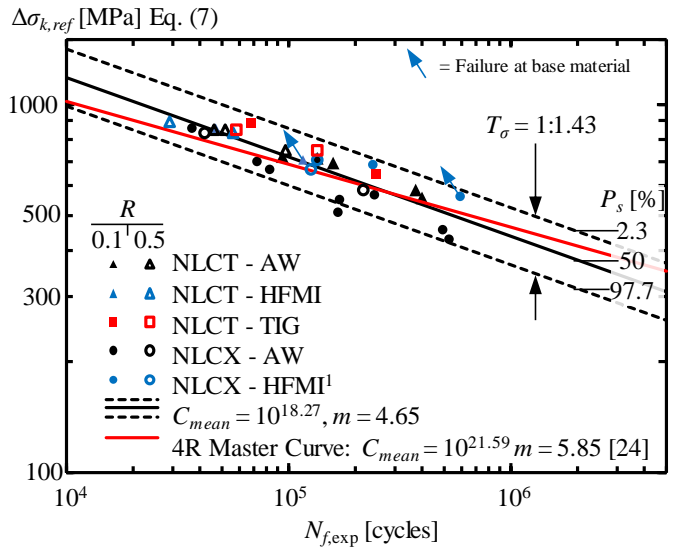

Fig 9. Fatigue test results using the $4 \mathrm{R}$ method with the mean and characteristic $S-N$ curves obtained by means of the MSSPD approach. ${ }^{1}$ For HFMI-treated NLCX-joints, the $R=0.1$ and $R=0.5$ data points represent the tests carried out using $R=0.1-0.2$ and $R=0.3-0.4$ loads, respectively (see details in Appendix 1).
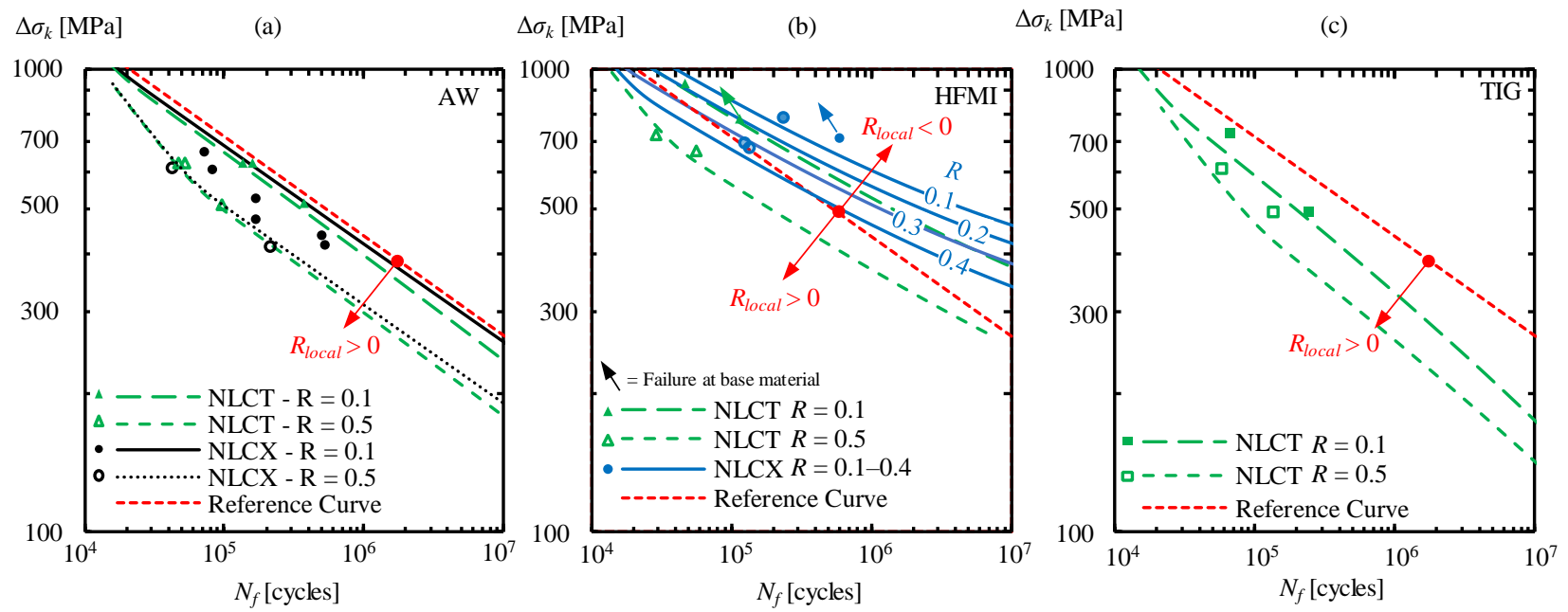
Fig 10. $S$ - $N$ curves of the $4 \mathrm{R}$ method with a $R_{\text {local }}$ correction, and the original data points $\left(N_{f, i}, \Delta \sigma_{k, i}\right)$ for the S1100 joints in (a) AW, (b) HFMI-treated and (c) TIG-dressed condition. For the reference curve, $C_{\text {mean }}=10^{18.27}$ and $m=4.65$ (see Fig. 9).

\section{DISCUSSION}

\subsection{Fatigue strength capacity}

The fatigue strength capacity of transverse NLC-joints made of UHSS was experimentally tested in the AW and PWT condition. The experimental data were collected from recently published studies $[17,30]$, and supplemented with additional tests on NLCX-joints made of S1100 grade steel. Due to the configuration of the test specimens, i.e. small-scale specimens and no deformations were prevented in the welding, almost zero residual stresses were obtained, also for the AW specimens, see Fig. 6, as also noted in prior studies [30,41]. In fact, the highest tensile residual stresses were obtained in the TIGdressed S1100 specimens, whereby a maximum of $200 \mathrm{MPa}$ parallel to the loading direction was measured. Nevertheless, to demonstrate the effect of high tensile residual stresses on the fatigue strength capacity, the tests were carried out using applied stress ratios of $R=0.1-0.5$.

The tests with the $R=0.1$ loading showed a good correspondence with the design guidelines [912]; a reasonable margin with respect to the design $S$ - $N$ curves with a survival probability of $P_{s}=97.7 \%$ was found. For the HFMI-treated joints at low stress ratios, i.e. $R=0.1$, FAT500 seemed to be applicable, see Fig. 3 and Table 6. However, the increasing mean stress level had a decreasing influence on the improvement level of the HFMI treatment. Due to the lack of design guidelines for the notch stress concept for the TIG-dressed joints [42], $r=r_{\text {true }}+1 \mathrm{~mm}$ was employed in this study, following the stress averaging concept with the fictitious notch rounding [43]. Using this concept, the $S-N$ curve for the TIGdressed joints $(R=0.1)$ did not reach the corresponding curve for the AW joints $(r=1.0 \mathrm{~mm})$. However, 
the TIG-dressed joints tested with $R=0.5$ loading, converged with the corresponding AW curve; see Fig. 3 and Table 6. In the TIG-dressed joints, the presence of tensile residual stresses make them less sensitive to the increase in the mean stress level. This finding is in agreement with the results acquired by Skriko et al. $[6,44]$

Of the geometry measurements conducted in this study, the average weld toe radius was determined to represent the test series, i.e. joints with similar joint configuration and welding parameters; see Fig. 7 and Table 7. A welding robot was used in the preparation of the test specimens and no significant variation was thus observed within the measurements and subsequent geometry analysis results. Although the HFMI and TIG treatments were performed manually, the geometrical variations were also minor in these specimens. In general, the test results (Fig. 3) showed that the specific $S$ - $N$ curves for the different $R$ ratios and joint conditions (AW or PWT) are required to reach a reasonable accuracy in fatigue strength predictions. To avoid the need for this, the $4 \mathrm{R}$ method was adopted using the concept $r=r_{\text {true }}+1 \mathrm{~mm}$ for all joints, regardless of the joint condition (AW, HFMI, TIG).

The aim of this study was to further verify the applicability of the $4 \mathrm{R}$ method for the fatigue strength assessment of fillet-welded joints made of UHSS. The results showed that the 4R method can be applied for UHSS joints in the AW and PWT condition, regardless of the applied stress ratio. In the previous work undertaken by Nykänen et al. [23,24], the applicability of the 4R method for joints in the AW and HFMI-treated conditions was introduced, following the $r_{r e f}=1.0 \mathrm{~mm}$ concept recommended by the IIW Recommendations [15]. Nevertheless, the fatigue test conducted at higher stress ratio, i.e. $R=$ 0.5, indicated that fatigue strength improvement with the HFMI treatment can be claimed also at high stress ratios; see Fig. 3. The main influencing factor for that was obviously the increase in weld toe radius, as shown in Table 7 . Consequently, the stress averaging concept, i.e. $r_{\text {true }}+1 \mathrm{~mm}$, was adopted 
different to a previous study [24] showing good accordance with fatigue test results in terms of the 4R method.

The results of the $4 \mathrm{R}$ analysis showed a drastic decrease in the scatter of the test results, i.e. all data points converged in a single $S-N$ curve with a scatter range $\left(P_{s}=97.7 \%: P_{s}=2.3 \%\right)$ of $T_{\sigma}=1: 1.43$; see

Fig. 9. This results in a mean fatigue strength of $C_{4 \mathrm{R}, \text { mean }}=10^{18.27}$ (FAT $=375 \mathrm{MPa}$ at two million cycles) and a characteristic fatigue strength capacity of $C_{4 \mathrm{R}, \text { char }}=10^{17.91}\left(P_{s}=97.7 \%\right.$, FAT $\left.=314 \mathrm{MPa}\right)$ with the slope of the $S$ - $N$ curve $m=4.65$. The present study estimated a steeper slope with respect to the previous studies related to the $4 \mathrm{R}$ method, in which $m=5.85$ was obtained [23,29]. Nevertheless, the Master Curve obtained by Nykänen and Björk [23] for C-Mn steels including various material strengths $\left(R_{p 0.2}=224-\right.$ $1100 \mathrm{MPa}$ ) fits the experimental results of this study, as shown in Fig 9. When conducting a statistical analysis with a similar slope of $m=5.85, C_{4 \mathrm{R} \text {, mean }}=10^{21.68}$ was received, which corresponds well with the Master Curve of $C_{4 \mathrm{R}, \text { mean }}=10^{21.59}$.

\subsection{Efficient fatigue design practices}

From the engineering design point of view, the $4 \mathrm{R}$ method poses challenges to designers in the selection of trustworthy $4 \mathrm{R}$ parameters, i.e. without drawing unconservative assumptions and yet without redundant conservatism. In this study, an X-ray diffractometer, and 2D geometry measurement devices were employed to measure the residual stresses and weld profiles, respectively, for the $4 \mathrm{R}$ analysis. In fatigue design engineering, such facilities are not always available and, thus, the worst-case assumptions, such as tensile residual stresses equal to yield strength and a sharp $r_{\text {true }}=0$ weld toe radius, are typically used to avoid making unconservative fatigue life predictions. This concept can also be adopted when using the 4R method [45]. For the HFMI treatment, a conservative assumption of $\sigma_{r e s}=-0.255 R_{m}$ was given in [24] based on the measurements of existing studies, and the assumption seems to correspond to 
the residual stress measurements of this study. Regarding the residual stresses after the TIG dressing, the authors did not find studies, in which the TIG dressing of UHSSs and subsequent residual stress measurements were conducted for joints in the high tensile residual stress field.

Nevertheless, the increasing demands for structural and weight optimization are leading to more comprehensive utilization of structural performance, and methods to examine the realized values are needed. In this regard, quality assurance in fabrication [46] plays an important role; the desired quality level must be reached and verified. Although there exist many non-destructive measurement techniques for measuring the residual stresses in the structures, they are not commonly used in the practical engineering work. To overcome the need for the measurements, simulation of welding processes $[47,48]$ and PWTs [49-51] for UHSSs can be adopted to estimate the residual stress state for the fatigue strength assessment, together with the analytical [52] and numerical [34] methods to estimate the stabilized residual stresses.

\subsection{Future work}

Within this study, HFMI treatment and, with a limited scope, TIG dressing were considered as PWTs for fillet-welded joints, showing the efficiency of the $4 \mathrm{R}$ method for the fatigue strength assessment of welded joints made of UHSS. To further validate the 4R method for TIG-dressed joints, additional fatigue tests and detailed research on the residual stress state after treatment for different steel grades should be carried out. In addition, the incorporation of other post-weld improvement techniques, such as burr grinding [33] and laser dressing [44], under the 4R methodology needs further verification. In the 4R method, the residual stress relaxation can be considered; see Fig. 4. Nevertheless, in the studied joints, stabilized residual stresses were not measured, and the effects of it on the use of the 4R method should be paid attention in future works. 
This study showed a decrease in the improvement level of the HFMI treatment when the $R$ ratio increases. Experimental tests were conducted at the intermediate regime, i.e. near 100000 cycles. It should be noted that the HFMI treatment shows a particularly beneficial effect at the high cycle regime, hence additional experimental tests should be carried out to verify the $4 \mathrm{R}$ method at this regime. The fatigue testing of HFMI-treated welded joints at the high cycle regime, however, may result in failures outside the joint area, particularly at low stress ratios, as also observed in this study. To diminish the affecting parameters causing scatter in the fatigue test results, small-scale specimens are typically preferred to study a certain phenomenon. As with many other fatigue design concepts, the 4R method also requires further validation by testing with large-scale specimens and structures.

\section{CONCLUSIONS}

Within this study, the experimental fatigue test data for fillet-welded joints with transverse attachments made of UHSS was extracted from literature. The tests were complemented with the fatigue tests conducted for the NLCX-joints made of the S1100 UHSS. All tests were carried out using CAL with the applied stress ratio of $R=0.1-0.5$. The fatigue strengths were obtained using conventional stress-based approaches; the nominal stress, structural HS stress and ENS method. The 4R method was employed to investigate the mean stress correction by means of the local stress ratio acting at the notch root. On the basis of the experimental work and subsequent fatigue analysis, the following conclusions can be drawn:

- The fatigue test results with low stress ratios, i.e. $R=0.1$, exceeded the characteristic curves $\left(P_{s}\right.$ $=97.7 \%)$ of the design codes and guidelines [9-12].

- The design curves [9-12] were unconservative for the joints in the AW condition and tested at high stress ratio, i.e. $R=0.5$. For the HFMI-treated joints tested at high stress ratio, higher fatigue strength was found than suggested by the IIW Recommendations [15]. 
- The conventional fatigue strength assessment methods, such as the nominal stress, HS and ENS concepts, recall specific $S-N$ curves for different PWTs, and careful consideration of applied stress ratio is needed to reach a reasonable accuracy in the fatigue strength assessment.

- The 4R method enables fatigue strength assessment of transverse fillet-welded UHSS joints with good accuracy regardless of joint condition or applied stress ratio using a single $S-N$ curve with the SWT mean stress correction.

\section{ACKNOWLEDGEMENTS}

The authors wish to thank Business Finland and SSAB Europe for the funding through the Digi-TuoTe project that enabled the experimental program and this study to be completed.

\section{REFERENCES}

[1] E. Harati, L. Svensson, L. Karlsson, M. Widmark, Effect of high frequency mechanical impact treatment on fatigue strength of welded $1300 \mathrm{MPa}$ yield strength steel, Int. J. Fatigue. 92 (2016) 96-106. doi:10.1016/j.ijfatigue.2016.06.019.

[2] T. Nykänen, T. Björk, R. Laitinen, Fatigue strength prediction of ultra high strength steel buttwelded joints, Fatigue Fract. Eng. Mater. Struct. 36 (2012) 469-482. doi:10.1111/ffe.12015.

[3] M. Leitner, S. Gerstbrein, M.J. Ottersböck, M. Stoschka, Fatigue strength of HFMI-treated highstrength steel joints under constant and variable amplitude block loading, Procedia Eng. 101 (2015) 251-258. doi:10.1016/j.proeng.2015.02.036.

[4] M. Leitner, M. Stoschka, W. Eichlseder, Fatigue enhancement of thin-walled, high-strength steel joints by high-frequency mechanical impact treatment, Weld. World. 58 (2014) 29-39. 
doi:10.1007/s40194-013-0097-4.

[5] J. Berg, N. Stranghöner, Fatigue behaviour of high frequency hammer peened ultra high strength steels, Int. J. Fatigue. 82 (2016) 35-48. doi:10.1016/j.ijfatigue.2015.08.012.

[6] T. Skriko, M. Ghafouri, T. Björk, Fatigue strength of TIG-dressed ultra-high-strength steel fillet weld joints at high stress ratio, Int. J. Fatigue. 94 (2017) 110-120. doi:10.1016/j.ijfatigue.2016.09.018.

[7] S.H.J. Van Es, M.H. Kolstein, R.J.M. Pijpers, F.S.K. Bijlaard, TIG-dressing of high strength butt welded connections - Part 2: Physical testing and modelling, Procedia Eng. 66 (2013) 126-137. doi:10.1016/j.proeng.2013.12.068.

[8] T. Dahle, Design fatigue strength of TIG-dressed welded joints in high-strength steels subjected to spectrum loading, Int. J. Fatigue. 20 (1998) 677-681. doi:10.1016/S0142-1123(98)00031-0.

[9] A. Hobbacher, Recommendations for Fatigue Design of Welded Joints and Components, 2nd ed., Springer International Publishing, Cham, 2016.

[10] DNVGL-RP-C203, Fatigue Design of Offshore Steel Structures, 2016.

[11] BS7608:2014 +A1:2015, Guide to Fatigue Design and Assessment of Steel Products, 2015.

[12] EN 1993-1-9, Eurocode 3 - Design of steel structures - Part 1-9: Fatigue, 2005.

[13] C.M. Sonsino, Effect of residual stresses on the fatigue behaviour of welded joints depending on loading conditions and weld geometry, Int. J. Fatigue. 31 (2009) 88-101. doi:10.1016/j.ijfatigue.2008.02.015.

[14] H.C. Y1ldırım, G.B. Marquis, Fatigue strength improvement factors for high strength steel welded joints treated by high frequency mechanical impact, Int. J. Fatigue. 44 (2012) 168-176. doi:10.1016/j.ijfatigue.2012.05.002.

[15] G.B. Marquis, Z. Barsoum, IIW Recommendations for the HFMI Treatment - For Improving the 
Fatigue Strength of Welded Joints, Springer Singapore, Singapore, 2016. doi:10.1007/978-981$10-2504-4$

[16] J. Hensel, T. Nitschke-pagel, K. Dilger, Fatigue Performance of Welded Steel Longitudinal Stiffeners, in: Proc. 22nd Int. Offshore Polar Eng. Conf. Held Rhodes, Greece, 17-22 June, 2012, 2012: pp. 187-192.

[17] A. Ahola, T. Skriko, T. Björk, Experimental investigation on the fatigue strength assessment of welded joints made of S1100 ultra-high-strength steel in as-welded and post-weld treated condition, in: A. Zingoni (Ed.), Proc. 7th Int. Conf. Struct. Eng. Mech. Comput. (SEMC 2019). Cape Town, South Africa, 2-4 Sept. 2019, 2019: pp. 1254-1259.

[18] J. Hensel, T. Nitschke-Pagel, K. Dilger, Residual Stress-Based Fatigue Design of Welded Structures, Mater. Perform. Charact. 7 (2018) 630-642. doi:10.1520/mpc20170113.

[19] J. Hensel, Mean stress correction in fatigue design under consideration of welding residual stress. Henry Granjon Prize Catecory C: Design and Structural Integrity. IIW-document XIII-2795-19, 2019.

[20] C. Cui, Q. Zhang, Y. Bao, J. Kang, Y. Bu, Fatigue performance and evaluation of welded joints in steel truss bridges, J. Constr. Steel Res. 148 (2018) 450-456. doi:10.1016/j.jcsr.2018.06.014.

[21] P. Luo, Q. Zhang, Y. Bao, Predicting weld root notch stress intensity factors for rib-to-deck welded joint under deck loading modes, Int. J. Fatigue. 128 (2019) 105212. doi:10.1016/j.ijfatigue.2019.105212.

[22] J. Li, Q. Zhang, Y. Bao, J. Zhu, L. Chen, Y. Bu, An equivalent structural stress-based fatigue evaluation framework for rib- to-deck welded joints in orthotropic steel deck, Eng. Struct. 196 (2019) 109304. doi:10.1016/j.engstruct.2019.109304.

[23] T. Nykänen, T. Björk, Assessment of fatigue strength of steel butt-welded joints in as-welded 
condition - Alternative approaches for curve fitting and mean stress effect analysis, Mar. Struct. 44 (2015) 288-310. doi:10.1016/j.marstruc.2015.09.005.

[24] T. Nykänen, T. Björk, A new proposal for assessment of the fatigue strength of steel butt-welded joints improved by peening (HFMI) under constant amplitude tensile loading, Fatigue Fract. Eng. Mater. Struct. 39 (2016) 566-582. doi:10.1111/ffe.12377.

[25] T. Nykänen, H. Mettänen, T. Björk, A. Ahola, Fatigue assessment of welded joints under variable amplitude loading using a novel notch stress approach, Int. J. Fatigue. 101 (2017) 177-191. doi:10.1016/j.ijfatigue.2016.12.031.

[26] K.N. Smith, T.H. Topper, P. Watson, A stress-strain function for the fatigue of metals, J Mater. 5 (1970) 767-778. doi:10.1179/1752270612Y.0000000008.

[27] Ö. Karakas, Consideration of mean-stress effects on fatigue life of welded magnesium joints by the application of the Smith-Watson-Topper and reference radius concepts, Int. J. Fatigue. 49 (2013) 1-17. doi:10.1016/j.ijfatigue.2012.11.007.

[28] J. Baumgartner, T. Bruder, Influence of weld geometry and residual stresses on the fatigue strength of longitudinal stiffeners, Weld. World. 57 (2013) 841-855. doi:10.1007/s40194-013-0078-7.

[29] T. Björk, H. Mettänen, A. Ahola, M. Lindgren, J. Terva, Fatigue strength assessment of duplex and super-duplex stainless steels by 4R method, Weld. World. 62 (2018) 1285-1300. doi:10.1007/s40194-018-0657-8.

[30] A. Ahola, T. Nykänen, T. Björk, Effect of loading type on the fatigue strength of asymmetric and symmetric transverse non-load carrying attachments, Fatigue Fract. Eng. Mater. Struct. 40 (2017) 670-682. doi:10.1111/ffe.12531.

[31] H.C. Yildırım, Recent results on fatigue strength improvement of high-strength steel welded joints, Int. J. Fatigue. 101 (2017) 408-420. doi:10.1016/j.ijfatigue.2016.10.026. 
[32] C.M. Sonsino, W. Fricke, F. De Bruyne, A. Hoppe, A. Ahmadi, G. Zhang, Notch stress concepts for the fatigue assessment of welded joints - Background and applications, Int. J. Fatigue. 34 (2012) 2-16. doi:10.1016/j.ijfatigue.2010.04.011.

[33] P.J. Haagensen, S.J. Maddox, IIW Recommendations on Post Weld Improvement of Steel and Aluminium Structures. IIW-document XIII-2200r7-07 (revision 6 July 2010), 2010.

[34] M. Leitner, M. Khurshid, Z. Barsoum, Stability of high frequency mechanical impact (HFMI) post-treatment induced residual stress states under cyclic loading of welded steel joints, Eng. Struct. 143 (2017) 589-602. doi:10.1016/j.engstruct.2017.04.046.

[35] C. Cui, Q. Zhang, Y. Bao, S. Han, Y. Bu, Residual stress relaxation at innovative both-side welded rib-to-deck joints under cyclic loading, J. Constr. Steel Res. 156 (2019) 9-17. doi:10.1016/j.jcsr.2019.01.017.

[36] M. Amraei, A. Ahola, S. Afkhami, A. Heidarpour, T. Björk, X.-L. Zhao, Effects of heat input on the mechanical properties of butt-welded high and ultra-high strength steels, Eng. Struct. 198 (2019) 109460. doi:j.engstruct.2019.109460.

[37] N.E. Dowling, Mechanical Behavior of Materials. Engineering Methods for Deformation, Fracture, and Fatigue, Prentice Hall, 2006.

[38] M. Leitner, Influence of effective stress ratio on the fatigue strength of welded and HFMI-treated high-strength steel joints, Int. J. Fatigue. $102 \quad$ (2017) 158-170. doi:10.1016/j.ijfatigue.2017.03.008.

[39] J. Baumgartner, T. Bruder, An efficient meshing approach for the calculation of notch stresses, Weld. World. 57 (2013) 137-145. doi:10.1007/s40194-012-0005-3.

[40] W.E. Deming, Statistical Adjustment of Data, Dover Publication Inc., 1943.

[41] M. Leitner, W. Mössler, A. Putz, M. Stoschka, Effect of post-weld heat treatment on the fatigue 
strength of HFMI-treated mild steel joints, Weld. World. 59 (2015) 861-873. doi:10.1007/s40194015-0265-9.

[42] J. Baumgartner, P.G. Ruiz, H.C. Yıldırım, Fatigue assessment of TIG-dressed joint with local approaches, in: IIW Intermed. Meet. Held Braunschweig, 23 March 2017. IIW-Document XIIIWG3-56-18, 2017.

[43] D. Radaj, C.M. Sonsino, W. Fricke, Fatigue Assessment of Welded Joints by Local Approaches, 2nd editio, Woodhead Publishing, Cambridge, 2006.

[44] T. Skriko, Dependence of manufacturing parameters on the performance quality of welded joints made of direct quenched ultra-high-strength steel. Doctoral Dissertation, Lappeenranta University of Technology, 2018.

[45] T. Björk, A. Ahola, T. Skriko, 4R method for consideration of the fatigue performance of welded joints - Background and applications, in: S.-L. Chan, T.-M. Chan, S. Zhu (Eds.), Ninth Int. Conf. Adv. Steel Struct. (ICASS 2018), Hong Kong, 2018: pp. 1159-1168. doi:10.18057/ICASS2018.P.141.

[46] T. Stenberg, Z. Barsoum, E. Åstrand, A. Ericson Öberg, C. Schneider, J. Hedegård, Quality control and assurance in fabrication of welded structures subjected to fatigue loading, Weld. World. 61 (2017) 1003-1015. doi:10.1007/s40194-017-0490-5.

[47] J. Hensel, T. Nitschke-pagel, K. Dilger, On the effects of austenite phase transformation on welding residual stresses in non-load carrying longitudinal welds, Weld. World. (2015) 179-190. doi:10.1007/s40194-014-0190-3.

[48] J. Zhu, M. Khurshid, Z. Barsoum, Accuracy of computational welding mechanics methods for estimation of angular distortion and residual stresses, Weld. World. (2019). doi:10.1007/s40194019-00746-9. 
[49] P. Ferro, F. Berto, M.N. James, A simplified model for TIG-dressing numerical simulation, Model. Simul. Mater. Sci. Eng. 25 (2017).

[50] C. Deng, Y. Niu, B. Gong, Y. Liu, D. Wang, Numerical assessment of fatigue design curve of welded T-joint improved by high-frequency mechanical impact (HFMI) treatment, Adv. Eng. Softw. 114 (2017) 154-162. doi:10.1016/j.advengsoft.2017.06.017.

[51] Y. Liu, B. Gong, C. Deng, C. Zhao, X. Liu, D. Wang, Numerical analysis of optimum treatment parameters by high frequency mechanical impact, J. Constr. Steel Res. 150 (2018) 23-30. doi:10.1016/j.jcsr.2018.08.004.

[52] S. Han, T. Lee, B. Shin, Residual stress relaxation of welded steel components under cyclic load, Steel Res. Int. 73 (2002) 414-420. doi:srin.200200008|.

[53] T. Skriko, T. Björk, T. Nykänen, Effects of weaving technique on the fatigue strength of transverse loaded fillet welds made of ultra-high-strength steel, Weld. World. 58 (2014) 377-387. doi:10.1007/s40194-014-0123-1. 


\section{APPENDICES}

Appendix A. Fatigue test data of S1100 NLCX specimens tested in this study.

\begin{tabular}{|c|c|c|c|c|c|c|c|c|c|c|c|}
\hline Specimen ID & $\begin{array}{l}\text { Joint } \\
\text { type }\end{array}$ & $\begin{array}{c}\text { Joint } \\
\text { condition }\end{array}$ & Material & $\begin{array}{l}\Delta \sigma_{\text {nom }} \\
{[\mathrm{MPa}]}\end{array}$ & $\begin{array}{c}\Delta \sigma_{h s}{ }^{*} \\
{[\mathrm{MPa}]}\end{array}$ & $\begin{array}{c}\Delta \sigma_{\text {ens }} \\
{[\mathrm{MPa}]}\end{array}$ & $\begin{array}{c}\Delta \sigma_{k, 4 \mathrm{R}} \\
{[\mathrm{MPa}]}\end{array}$ & $\begin{array}{l}R \\
{[-]}\end{array}$ & $\begin{array}{c}R_{\text {eff }} \\
{[-]}\end{array}$ & $\begin{array}{c}N_{f, \text { exp }} \\
\text { [cycles] }\end{array}$ & Remarks \\
\hline S11_NLCX_1 & NLCX & $\mathrm{AW}$ & S1100 & 314 & 312 & 719 & 663 & 0.1 & 0.12 & 71872 & \\
\hline S11_NLCX_2 & NLCX & AW & S1100 & 301 & 317 & 721 & 610 & 0.1 & 0.12 & 82578 & \\
\hline S11_NLCX_3 & NLCX & AW & S1100 & 254 & 247 & 572 & 527 & 0.1 & 0.10 & 169415 & \\
\hline S11_NLCX_4 & NLCX & AW & S1100 & 231 & 241 & 549 & 476 & 0.1 & 0.13 & 167322 & \\
\hline S11_NLCX_5 & NLCX & AW & S1100 & 206 & 205 & 472 & 438 & 0.1 & 0.10 & 496828 & \\
\hline S11_NLCX_6 & NLCX & AW & S1100 & 201 & 196 & 453 & 417 & 0.1 & 0.08 & 528328 & \\
\hline S11_NLCX_7 & NLCX & AW & S1100 & 291 & 294 & 675 & 613 & 0.5 & 0.50 & 42103 & \\
\hline S11_NLCX_8 & NLCX & AW & S1100 & 193 & 197 & 450 & 415 & 0.5 & 0.50 & 216073 & \\
\hline S11_NLCX_9H & NLCX & HFMI & S1100 & 444 & 448 & 1029 & 712 & 0.1 & 0.11 & 592164 & Failure at base material \\
\hline S11_NLCX_10H & NLCX & HFMI & S1100 & 409 & 419 & 958 & 676 & 0.4 & 0.38 & 135617 & \\
\hline S11_NLCX_11H & NLCX & HFMI & S1100 & 420 & 432 & 987 & 696 & 0.3 & 0.30 & 125826 & \\
\hline S11_NLCX_12H & NLCX & HFMI & S1100 & 452 & 412 & 968 & 787 & 0.2 & 0.18 & 238488 & \\
\hline
\end{tabular}

* Corresponding to the failure locations. In some specimens, the failure occurred at the opposite side of specimen to the side of maximum HS stress. The

HS stresses corrected to correspond the stress value at the failure location, as shown in [53]. Consequently, $\Delta \sigma_{h s}<\Delta \sigma_{\text {nom }}$. 
Appendix B. Fatigue test data of S960 and S1100 specimens tested in $[17,30]$.

\begin{tabular}{|c|c|c|c|c|c|c|c|c|c|c|c|}
\hline Specimen ID & $\begin{array}{l}\text { Joint } \\
\text { type }\end{array}$ & $\begin{array}{c}\text { Joint } \\
\text { condition }\end{array}$ & Material & $\begin{array}{l}\Delta \sigma_{\text {nom }} \\
{[\mathrm{MPa}]}\end{array}$ & $\begin{array}{c}\Delta \sigma_{h s} \\
{[\mathrm{MPa}]}\end{array}$ & $\begin{array}{l}\Delta \sigma_{\text {ens }} \\
{[\mathrm{MPa}]}\end{array}$ & $\begin{array}{l}\Delta \sigma_{k, 4 \mathrm{R}} \\
{[\mathrm{MPa}]}\end{array}$ & $\begin{array}{l}R \\
{[-]}\end{array}$ & $\begin{array}{c}R_{\text {eff }} \\
{[-]}\end{array}$ & $\begin{array}{c}N_{f, \exp } \\
\text { [cycles] }\end{array}$ & Remarks \\
\hline S11_NLCT_1 & NLCT & AW & S1100 & 311 & 365 & 683 & 631 & 0.1 & 0.11 & 159573 & \\
\hline S11_NLCT_3 & NLCT & AW & S1100 & 310 & 365 & 683 & 631 & 0.1 & 0.16 & 135643 & \\
\hline S11_NLCT_5 & NLCT & AW & S1100 & 250 & 297 & 558 & 515 & 0.1 & 0.17 & 376238 & \\
\hline S11_NLCT_2 & NLCT & AW & S1100 & 313 & 363 & 680 & 628 & 0.5 & 0.51 & 46422 & \\
\hline S11_NLCT_4 & NLCT & AW & S1100 & 318 & 364 & 681 & 629 & 0.5 & 0.51 & 52181 & \\
\hline S11_NLCT_6 & NLCT & AW & S1100 & 254 & 296 & 554 & 511 & 0.5 & 0.53 & 97383 & \\
\hline S11_NLCT_7H & NLCT & HFMI & S1100 & 604 & 667 & 1242 & 929 & 0.1 & 0.10 & 47174 & \\
\hline S11_NLCT_8H & NLCT & HFMI & S1100 & 526 & 565 & 1048 & 784 & 0.1 & 0.10 & 116617 & Failure at base material \\
\hline S11_NLCT_9H & NLCT & HFMI & S1100 & 465 & 518 & 965 & 721 & 0.5 & 0.48 & 29305 & \\
\hline S11_NLCT_10H & NLCT & HFMI & S1100 & 423 & 475 & 888 & 664 & 0.5 & 0.48 & 56474 & \\
\hline S11_NLCT_11T & NLCT & TIG & S1100 & 446 & 602 & 730 & 730 & 0.1 & 0.16 & 67404 & \\
\hline S11_NLCT_13T & NLCT & TIG & S1100 & 289 & 408 & 494 & 494 & 0.1 & 0.22 & 247632 & \\
\hline S11_NLCT_12T & NLCT & TIG & S1100 & 434 & 507 & 612 & 612 & 0.5 & 0.52 & 58140 & \\
\hline S11_NLCT_14T & NLCT & TIG & S1100 & 323 & 408 & 493 & 493 & 0.5 & 0.54 & 135812 & \\
\hline AAT5 & NLCT & AW & S960 & 299 & 377 & 715 & 664 & 0.1 & 0.21 & 93948 & \\
\hline AAT6 & NLCT & AW & S960 & 210 & 284 & 541 & 503 & 0.1 & 0.25 & 399921 & \\
\hline AAX5 & NLCX & AW & S960 & 373 & 371 & 864 & 796 & 0.1 & 0.16 & 36761 & \\
\hline AAX6 & NLCX & AW & S960 & 250 & 251 & 583 & 537 & 0.1 & 0.12 & 244214 & \\
\hline
\end{tabular}

